\title{
Endovascular mechanical thrombectomy for superior sagittal sinus thrombosis in a patient with T-lymphoblastic lymphoma treated with L-asparaginase
}

\author{
Adam Bond, ${ }^{1}$ Caroline Furness, ${ }^{2}$ Alex Mortimer ${ }^{3}$
}

'Department of Haematology, Bristol Haematology and Oncology Centre, Bristol, UK ${ }^{2}$ Children's \& Adolescent Services, Royal Marsden NHS Foundation Trust, London, UK ${ }^{3}$ Department of Neuroradiology, North Bristol NHS Trust, Bristol, UK

\section{Correspondence to}

Dr Adam Bond,

adam.bond3@uhbristol.nhs.uk

Accepted 1 May 2019

\section{DESCRIPTION}

A 32-year-old woman was diagnosed with T-lymphoblastic lymphoma/T-lymphoblastic leukaemia (ALL) while 20 weeks pregnant. She underwent termination of pregnancy (TOP) and commenced phase 1 ALL induction therapy following the UKALL14 protocol (off-trial) with daunorubicin, vincristine and dexamethasone. Pegylated-asparaginase was initially omitted in view of thrombotic risk, with additional catch-up doses administered when more than 6 weeks post-TOP. She subsequently achieved a complete metabolic remission by positron emission tomography-CT and bone marrow minimal residual disease negativity by flow cytometry.

During cycle 3 consolidation, 10 days following the last dose of pegylated-asparaginase, she presented with refractory generalised tonic-clonic seizures requiring induction of anaesthesia, intubation and mechanical ventilation. Magnetic resonance venography (MRV) confirmed thrombosis of the superior sagittal sinus and frontal cortical veins (figure 1), with secondary infarction and haemorrhage (demonstrated on parenchymal imaging). Despite commencing unfractionated heparin with anti-Xa activity within the therapeutic range and antithrombin activity over 70\%, she developed progressive seizures and hemiparesis with further secondary haemorrhage. She therefore proceeded to endovascular mechanical thrombectomy, following which she has made an excellent recovery with normal

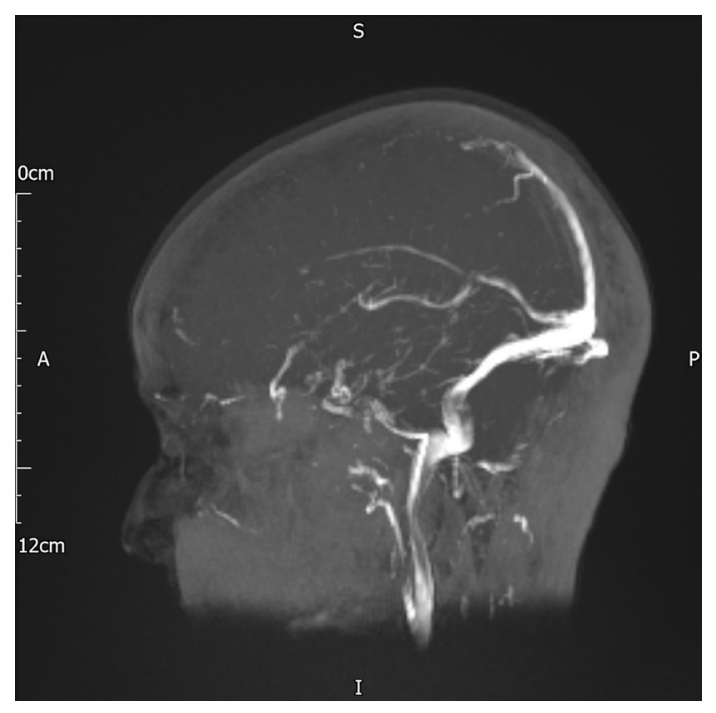

Figure 1 Cerebral magnetic resonance venogram demonstrating absent flow in the superior sagittal sinus.

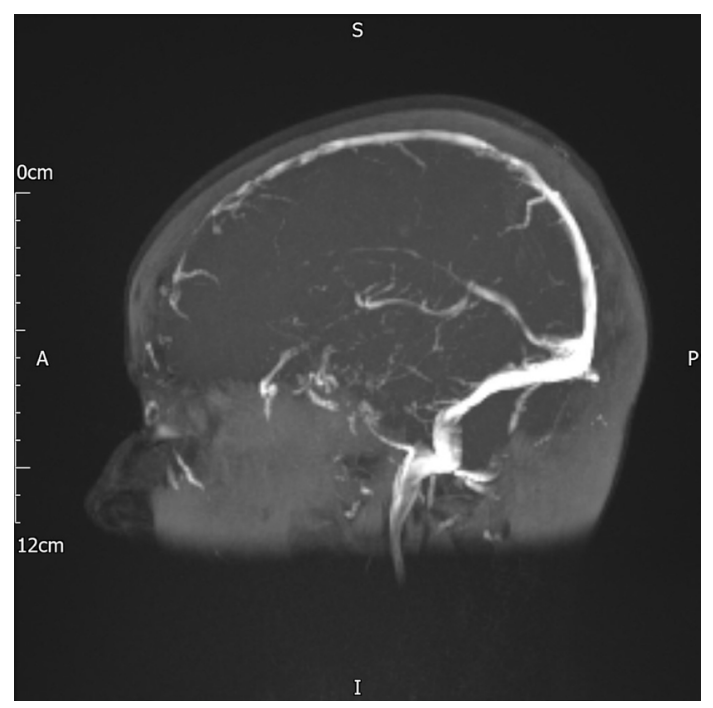

Figure 2 Cerebral magnetic resonance venogram demonstrating recanalisation of the superior sagittal sinus.

cognitive function and only mild residual weakness. Repeat MRV after 1 month demonstrated venous recanalisation (figure 2).

\section{Learning points}

- Cerebral venous sinus thrombosis is a wellrecognised complication in patients with T-lymphoblastic lymphoma/T-lymphoblastic leukaemia receiving L-asparaginase, with an ongoing risk outside the induction period.

- Although anticoagulation is the mainstay treatment, endovascular mechanical thrombectomy is increasingly being used for refractory patients, with an excellent outcome in this case.

Contributors $A B$ wrote the manuscript. CF was the consultant responsible for the patient's care. AM performed the endovascular mechanical thrombectomy. All authors read and approved the final version of the manuscript.

Funding The authors have not declared a specific grant for this research from any funding agency in the public, commercial or not-for-profit sectors.

Competing interests None declared.

Patient consent for publication Obtained.

Provenance and peer review Not commissioned; externally peer reviewed. 
Images in...

Copyright 2019 BMJ Publishing Group. All rights reserved. For permission to reuse any of this content visit https://www.bmj.com/company/products-services/rights-and-licensing/permissions/

BMJ Case Report Fellows may re-use this article for personal use and teaching without any further permission.

Become a Fellow of BMJ Case Reports today and you can:

- Submit as many cases as you like

- Enjoy fast sympathetic peer review and rapid publication of accepted articles

Access all the published articles

- Re-use any of the published material for personal use and teaching without further permission

For information on Institutional Fellowships contact consortiasales@bmjgroup.com

Visit casereports.bmj.com for more articles like this and to become a Fellow 